\title{
Assessment between Dopamine Receptor D2 (DRD2) Polymorphisms and Schizophrenia in Korean Population
}

\author{
Ah Rang Cho', Sang Min Lee ${ }^{1}$, Won Sub Kang', Su Kang Kim², Joo-Ho Chung ${ }^{2}$ \\ 'Department of Neuropsychiatry, ${ }^{2}$ Department of Pharmacology and Kohwang Medical Research Institute, Kyung Hee University, School \\ of Medicine, Seoul, Korea
}

\begin{abstract}
Objective: The aim of this study was to investigate whether single nucleotide polymorphisms (SNPs) of dopamine receptor D2 (DRD2) are associated with schizophrenia in Korean population.

Methods: Four SNPs (rs4648317, rs7131056, rs4936270, and rs1076562) of DRD2 were selected and genotyped by direct sequencing in 197 schizophrenia patients and 370 control subjects. SNPAnalyzer, SNPStats, and Haploview version 4.2 programs were performed to analyze the genetic data. Multiple logistic regression models (codominant1, codominant2, dominant, recessive, overdominant, and log-additive) were used to evaluate the odds ratios (ORs), 95\% confidence intervals (Cls), and $p$ values. For multiple testing, $p$ values $(p)$ were re-evaluated by Bonferroni's correction.

Results: The genotype frequency of DRD2 rs4936270 SNP was associated with the development of schizophrenia ( $p=0.0007$, $\mathrm{OR}=1.71,95 \% \mathrm{Cl}=1.16-2.52$ in the codominant1 model; $p=0.011, \mathrm{OR}=1.63,95 \% \mathrm{Cl}=1.12-2.37$ in the dominant model; $p=0.035$, $\mathrm{OR}=1.41,95 \% \mathrm{Cl}=1.03-1.95$ in the log-additive model). The allele frequency of rs4936270 was also associated with the development of schizophrenia ( $p=0.024, \mathrm{OR}=1.45,95 \% \mathrm{Cl}=1.05-1.98$ ). After Bonferroni's correction, the genotype distribution of $r(4936270$ was still related to the development of schizophrenia ( $p^{c}=0.0028$ in the codominant 1 model; $p^{c}=0.044$ in the dominant model). A linkage disequilibrium block consisted of rs4648317, rs7131056, and rs4936270. The CAT haplotype frequency was different between schizophrenia and controls ( $p=0.039$ ).

Conclusion: These results suggest that DRD2 SNPs may be associated with the development of schizophrenia in Korean population.
\end{abstract}

KEY WORDS: Dopamine receptor D2; Haplotypes; Schizophrenia; Single nucleotide polymorphism.

\section{INTRODUCTION}

Schizophrenia is a complex psychiatric disorder characterized by a marked thinking disturbance and is also a devastating disorder with a high degree of morbidity. ${ }^{1}$ Twin, adoption, and family studies have implicated that schizophrenia is one of genetic disorders with high heritability. ${ }^{2,3)}$ Several lines of evidences suggest that genetic factors contribute to the susceptibility of schizophrenia. ${ }^{4,5)}$ Recently, many genetic studies have been reported the relationship between schizophrenia and single nucleotide polymorphisms (SNPs) of candidate genes and/or copy number variants and susceptible loci through

\footnotetext{
Received: March 6, 2012 / Revised: April 16, 2012

Accepted: April 21, 2012

Address for correspondence: Joo-Ho Chung, MD, PhD Department of Pharmacology and Kohwang Medical Research Institute, Kyung Hee University School of Medicine, 26 Kyunghee-daero, Dongdaemun-gu, Seoul 130-701, Korea Tel: +82-2-961-0281, Fax: +82-2-968-0560

E-mail: jhchung@khu.ac.kr
}

the genome-wide association study. ${ }^{6-8)}$

The dopamine receptor D2 (DRD2) is a G protein-coupled receptor inhibiting adenylyl cyclase activity. This receptor is located on postsynaptic dopaminergic neurons involved in reward-mediating mesocorticolimbic pathways. ${ }^{9)}$ DRD2 consists of 2 isoforms, D2S (shot isoform) and D2L (long isoform). D2L has an additional 29 amino acids in the third intracellular loop, compared to D2S. D2L acts at postsynaptic sites and D2S plays a role in presynaptic autoreceptor functions. The pharmacological effects of haloperidol are absent in D2L deficient mice, suggesting D2L is targeted by haloperidol. ${ }^{10)}$ The DRD2 signaling plays a crucial role in the physiopathologic conditions such as locomotion and drug abuse. It is well-known that DRD2 may be related to the susceptibility of schizophrenia. Antipsychotic drugs block postsynaptic DRD2. Postmortem studies have reported that DRD2 density is increased in the caudate, putamen, and nucleus accumbens of schizophrenia patients. ${ }^{11)}$ Drugs in- 
creasing dopaminergic activity such as levodopa and bromocriptine aggravate schizophrenic symptoms. ${ }^{12-15)}$ Although DRD2 is implicated in the pathogenesis of schizophrenia, the genetic determinants still remain.

In this study, we investigated whether SNPs of the DRD2 gene are associated with schizophrenia in a Korean population.

\section{METHODS}

\section{Study Subjects}

Schizophrenia patients were enrolled among participants who visited at the departments of neuropsychiatry in the East-West Neomedical Center and Kyung Hee Medical Center (Seoul, Korea). A total of 197 Korean schizophrenia patients and 370 healthy subjects were recruited. The schizophrenia group $(n=197)$ comprised 113 males and 84 female, and the mean age of schizophrenia patients was $42.2 \pm 10.8$ (mean \pm standard deviation) years. The control group $(n=370)$ consisted of 187 males and 183 females. The mean age of controls was $44.3 \pm 6.3$ years. Patients were diagnosed as schizophrenia by well-trained psychiatrists according to the Diagnostic and Statistical Manual of Mental Disorders (fourth edition) using available information from interviews and clinical records. Control subjects were recruited among

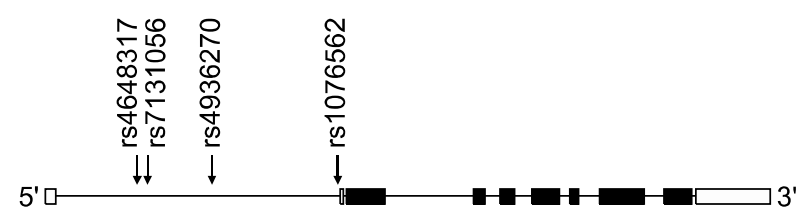

Fig. 1. Gene map and location of single nucleotide polymorphisms (SNPs) in the DRD2 gene. Exons are marked with box. The coding regions are black boxes and untranslation regions are white boxes. Arrow indicates the location of each SNP. individuals assessed as mentally healthy through a general health examination program. Subjects with neurological diseases and any severe diseases were excluded. This study was carried out in accordance with the guidelines of the Helsinki Declaration and approved by the Ethics Review Committee of Medical Research Institute, Kyung Hee University Medical Center, Seoul, Republic of Korea. Written informed consent was obtained from each subject.

\section{Genotyping}

In this study, we focused on intronic SNPs (iSNPs) in the intron 1 region of DRD2: (1) we wanted to find out new SNPs related to schizophrenia susceptibility; (2) the methylation of $\mathrm{CpG}$ islands has been identified in the intron 1 of DRD2. ${ }^{16)}$ We searched DRD2 SNPs in the NCBI websites (www.ensembl.org, www.broad.mit.edu/mpg/ tagger, www.hapmap.org, and www.ncbi.nlm.nih.gov/ SNP, BUILD135). SNPs with $<5 \%$ minor allele frequency, $<10 \%$ heterozygosity, and monomorphic genotype in Asian populations were excluded. Finally, we selected four iSNPs (rs4648317, rs7131056, rs4936270, and rs1076562) (Fig. 1). Peripheral blood samples were collected in EDTA or heparin tubes from each subject. DNA was isolated using the DNA Isolation Kit for Cells and Tissues (Roche, Indianapolis, IN, USA) and the genotypes of four SNPs were determined by direct sequencing (MACROGEN, Seoul, Korea). Polymerase chain reactions (PCRs) using the sense and antisense primers of each SNP were conducted (Table 1). The PCR products were sequenced by an ABI PRISM 3730XL analyzer (PE Applied Biosystems, Foster City, CA, USA) and SeqManII software (DNASTAR, Madison, WI, USA) was used to analyze the sequencing data.

\section{Statistical Analysis}

SNPStats (http://bioinfo.iconcologia.net/index.php?module $=$ Snpstats) and SNPAnalyzer Pro (ISTECH, Goyang,

Table 1. Primer sequences of DRD2 SNPs

\begin{tabular}{ccll}
\hline Gene & SNP & & \multicolumn{1}{c}{ Sequence $\left(5^{\prime}-3^{\prime}\right)$} \\
\hline DRD2 & rs4648317 & Forward & GGTACAGGGGATTCCAAGGAG \\
& Intron & Reverse & AGAGGCACATGGACACTGCTGG \\
& rs1076562 & Forward & TATTGAACCTCCCCAGACTCA \\
& Intron & Reverse & CAACAGCCAATTATCAAGCAA \\
& rs4936270 & Forward & TCTAGGACTGGTGGGAGGAAG \\
& Intron & Reverse & AAGAAAGTGCTGCTTTTCCAG \\
& rs7131056 & Forward & GCTTCTGCCCACAGTACATT \\
& Intron & Reverse & GCAGGGGGAAATAAGAGGCAAG \\
\hline
\end{tabular}

DRD2, dopamine receptor D2; SNP, singe nucleotide polymorphism; bp, base pair. 
Korea) were used to calculate odds ratios (ORs), 95\% confidence intervals (CIs), and $p$ values adjusting for age and gender as covariables. Multiple logistic regression models were employed to analyze genetic data: codominant1 (major allele homozygotes vs. heterozygotes), codominant2 (major allele homozygotes vs. minor allele homozygotes), dominant (major allele homozygotes vs. heterozygotes + minor allele homozygotes), recessive (major allele homozygotes + heterozygotes vs. minor allele homozygotes), overdominant (major allele homozygotes + minor allele homozygotes vs. heterozygotes), and log-additive (major allele homozygotes vs. heterozygotes vs. minor allele homozygotes). The linkage disequilibrium (LD) block and haplotypes were evaluated using Haploview 4.2 (Daly Lab, Cambridge, MA, USA). Bonferroni's correction was applied by multiplying the $p$ values by the number of SNPs. Hardy-Weinberg equilibrium (HWE) was calculated using the chi-squared test. Statistical significance was evaluated using SPSS ver. 15.0 (SPSS Inc., Chicago, IL, USA) and set at $p<0.05$.

\section{RESULTS}

\section{Genotype Analysis}

The genotype and allele frequencies of the four examined SNPs are shown in Table 2. Four iSNPs (rs4648317, rs7131056, rs4936270, and rs1076562) of DRD2 were in HWE in the schizophrenia and control groups, respectively ( $p>0.05$, data not shown). Three SNPs (rs4648317, rs7131056, and rs1076562) were not associated with schizophrenia. However, the genotype frequency of rs4936270 was associated with the development of schizophrenia $(p=0.0007, \mathrm{OR}=1.71,95 \% \mathrm{CI}=1.16-2.52$ in the codominant 1 model; $p=0.011, \mathrm{OR}=1.63,95 \% \mathrm{CI}=1.12-2.37$ in the dominant model; $p=0.035, \mathrm{OR}=1.41,95 \% \mathrm{CI}=$ $1.03-1.95$ in the log-additive model). The allele frequency of rs4936270 was also associated with the development of schizophrenia ( $p=0.024, \mathrm{OR}=1.45,95 \% \mathrm{CI}=1.05-1.98)$. The $\mathrm{C} / \mathrm{T}$ genotype and $\mathrm{C}$ allele frequencies of rs 4936270 was higher in the schizophrenia group (34.7 and 20.3\%) than in the control group (23.5 and 15.0\%). After Bonferroni's correction, the genotype distribution of

Table 2. Genotype and allele frequencies of DRD2 SNPs in control subjects and schizophrenia patients

\begin{tabular}{|c|c|c|c|c|c|c|c|c|c|c|}
\hline \multirow{2}{*}{ SNP } & & \multirow{2}{*}{ Type } & \multicolumn{2}{|c|}{ Control } & \multicolumn{2}{|c|}{ SPR } & \multirow{2}{*}{ Model } & \multirow{2}{*}{ OR $(95 \% \mathrm{Cl})$} & \multirow{2}{*}{$p$} & \multirow{2}{*}{$\begin{array}{l}\text { Bonferroni's } \\
\text { correction } p\end{array}$} \\
\hline & & & $\mathrm{n}$ & $\%$ & $\mathrm{n}$ & $\%$ & & & & \\
\hline \multirow{7}{*}{$\begin{array}{l}\text { rs4648317 } \\
\text { Intron }\end{array}$} & Genotype & $\mathrm{C} / \mathrm{C}$ & 133 & 36.0 & 71 & 36.2 & Codominant 1 & $0.99(0.67-1.46)$ & 0.96 & 1.00 \\
\hline & & $\mathrm{C} / \mathrm{T}$ & 175 & 47.3 & 95 & 48.5 & Codominant2 & $0.91(0.54-1.55)$ & 0.74 & 1.00 \\
\hline & & $\mathrm{T} / \mathrm{T}$ & 62 & 16.8 & 30 & 15.3 & Dominant & $0.97(0.67-1.40)$ & 0.87 & 1.00 \\
\hline & & & & & & & Recessive & $0.92(0.57-1.48)$ & 0.73 & 1.00 \\
\hline & & & & & & & Log-additive & $0.96(0.75-1.24)$ & 0.77 & 1.00 \\
\hline & Allele & $\mathrm{C}$ & 441 & 59.6 & 237 & 60.2 & & 1 & & \\
\hline & & $T$ & 299 & 40.4 & 157 & 39.8 & & $0.98(0.76-1.25)$ & 0.86 & 1.00 \\
\hline \multirow{7}{*}{$\begin{array}{l}\text { rs } 1076562 \\
\text { Intron }\end{array}$} & Genotype & $A / A$ & 95 & 25.7 & 54 & 27.6 & Codominant1 & $0.96(0.63-1.46)$ & 0.85 & 1.00 \\
\hline & & $\mathrm{A} / \mathrm{G}$ & 181 & 48.9 & 100 & 51.0 & Codominant2 & $0.82(0.50-1.35)$ & 0.44 & 1.00 \\
\hline & & $G / G$ & 94 & 25.4 & 42 & 21.4 & Dominant & $0.91(0.62-1.36)$ & 0.65 & 1.00 \\
\hline & & & & & & & Recessive & $0.84(0.55-1.28)$ & 0.42 & 1.00 \\
\hline & & & & & & & Log-additive & $0.91(0.71-1.16)$ & 0.45 & 1.00 \\
\hline & Allele & $A$ & 371 & 50.1 & 210 & 53.3 & & 1 & & \\
\hline & & $G$ & 369 & 49.9 & 184 & 46.7 & & $0.88(0.69-1.13)$ & 0.31 & 1.00 \\
\hline \multirow{7}{*}{$\begin{array}{l}\text { rs4936270 } \\
\text { Intron }\end{array}$} & Genotype & $\mathrm{C} / \mathrm{C}$ & 271 & 73.2 & 122 & 62.2 & Codominant1 & $1.71(1.16-2.52)$ & 0.0007 & 0.0028 \\
\hline & & $\mathrm{C} / \mathrm{T}$ & 87 & 23.5 & 68 & 34.7 & Codominant2 & $1.05(0.38-2.89)$ & 0.93 & 1 \\
\hline & & $\mathrm{T} / \mathrm{T}$ & 12 & 3.2 & 6 & 3.1 & Dominant & $1.63(1.12-2.37)$ & 0.011 & 0.044 \\
\hline & & & & & & & Recessive & $0.89(0.32-2.43)$ & 0.82 & 1.00 \\
\hline & & & & & & & Log-additive & $1.41(1.03-1.95)$ & 0.035 & 0.14 \\
\hline & Allele & C & 629 & 85.0 & 314 & 79.7 & & 1 & & \\
\hline & & $T$ & 111 & 15.0 & 80 & 20.3 & & $1.45(1.05-1.98)$ & 0.024 & 0.96 \\
\hline \multirow{7}{*}{$\begin{array}{l}\text { rs7131056 } \\
\text { Intron }\end{array}$} & Genotype & $\mathrm{C} / \mathrm{C}$ & 121 & 32.7 & 62 & 31.6 & Codominant 1 & $0.98(0.65-1.46)$ & 0.91 & 1.00 \\
\hline & & $C / A$ & 174 & 47.0 & 92 & 46.9 & Codominant2 & $1.09(0.66-1.77)$ & 0.75 & 1.00 \\
\hline & & $A / A$ & 75 & 20.3 & 42 & 21.4 & Dominant & $1.01(0.69-1.47)$ & 0.96 & 1.00 \\
\hline & & & & & & & Recessive & $1.10(0.72-1.69)$ & 0.66 & 1.00 \\
\hline & & & & & & & Log-additive & $1.03(0.81-1.32)$ & 0.78 & 1.00 \\
\hline & Allele & $\mathrm{C}$ & 416 & 56.2 & 218 & 55.3 & & 1 & & \\
\hline & & $A$ & 324 & 43.8 & 176 & 44.7 & & $1.04(0.81-1.33)$ & 0.78 & 1.00 \\
\hline
\end{tabular}

DRD2, dopamine receptor D2; SNP, singe nucleotide polymorphism; SPR, schizophrenia; OR, odds ratio; Cl, confidence interval. The $p$ values were calculated from logistic regression analysis adjusting age and sex. Bold number indicates significant association. 
rs4936270 showed statistical difference between schizophrenia and controls $\left(p^{c}=0.0028\right.$ in the codominant 1 mod$\mathrm{el} ; p^{c}=0.044$ in the dominant model). These results suggest that rs4936270 may be a risk factor for schizophrenia development.

\section{Linkage Disequilibrium and Haplotypes}

In order to evaluate the LD block and haplotypes of the four tested SNPs, we used Haploview 4.2 program. In Fig. 2, a LD block was made among rs4648317, rs7131056, and rs4936270 SNPs in the control group (rs4648317 and rs7131056, $\mathrm{D}^{\prime}=1, \mathrm{r}^{2}=0.528$; rs7131056 and rs4936270, $\mathrm{D}^{\prime}=1, \quad \mathrm{r}^{2}=0.227 ; \quad \mathrm{rs} 4648317$ and $\mathrm{rs} 4936270, \mathrm{D}^{\prime}=1$, $\left.\mathrm{r}^{2}=0.120\right)$. We also investigated the association between the haplotypes and schizophrenia. As shown in Table 3, frequency in four haplotypes showed $>0.1$. The distribution of TCC, CAC, CAT, CCC haplotypes was 0.400 , $0.275,0.166$, and 0.157 , respectively. The CAT haplotype was weakly associated with the development of schizophrenia ( $p=0.039$ ). In addition, the genotype frequencies
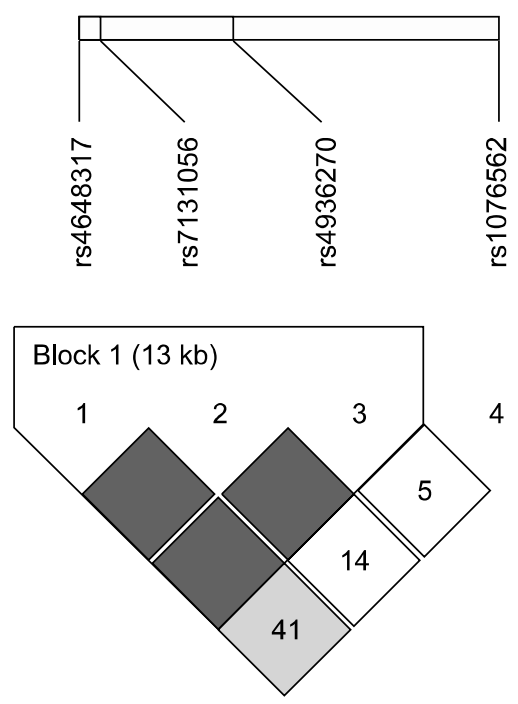

Fig. 2. Linkage disequilibrium block consists of rs4648317, rs7131056, and rs4936270. of the four examined SNPs (rs4648317, rs1076562, rs4936270, and rs7131056) were compared to those of European and other East Asian populations. The genotype frequencies of three SNPs (rs4648317, rs1076562, and rs7131056) were similar to those of Japanese, whereas the genotype frequencies of rs4936270 were similar to those of European (Table 4).

\section{Sample Power}

The power of the sample size was estimated using a genetic power calculator (http://pngu.mgh.harvard.edu/ purcell/ gpc). When the conditions of the sample power $(\alpha=0.05$, risk $=$ two-fold, the number of case $=80 \%$ power) were employed, we had 0.9143 for rs4648317 $(n=138), 0.9251$ for rs7131056 $(\mathrm{n}=133), 0.9184$ for $\mathrm{rs} 4936270(\mathrm{n}=136)$, and 0.8906 for $\mathrm{rs} 1076562(\mathrm{n}=151)$. Therefore, our case-control study was sufficiently powerful to study a positive correlation.

\section{DISCUSSION}

A number of studies have been published the relationship between DRD2 SNPs and schizophrenia. Betcheva et $a l .{ }^{17)}$ demonstrated that rs6277 (C957T, Pro319Pro) was significantly associated with schizophrenia after the replication study using independent sample set $(\mathrm{OR}=1.76$, $\mathrm{p}=0.001)$. Fan et al. ${ }^{18)}$ reported that $\mathrm{T}$ allele of rs6277 (Pro319Pro) was weakly associated with schizophrenia ( $\mathrm{OR}=1.58,95 \% \mathrm{CI}=1.03-2.43, p=0.034)$, while the genotype and allele frequencies of rs6275 (C939T, His313His) were not associated with schizophrenia in Chinese Han population. They suggest that rs6277 $\mathrm{T}$ allele may play a role in the genetic vulnerability for schizophrenia. A missense SNP rs1801028 (Ser311Cys) was reported to have an effect on risk for schizophrenia. ${ }^{19)}$ In contrast, Glatt and co-workers $^{20)}$ did not find a significant effect of rs 1801028 for association of schizophrenia in a family-based study. A study using in Southern Indian population found an association between the genotype distribution of rs6275 and

Table 3. Haplotype analysis of DRD2 SNPs in control subjects and schizophrenia patients

\begin{tabular}{|c|c|c|c|c|c|c|c|}
\hline \multirow{2}{*}{ Haplotype } & \multirow{2}{*}{ Frequency } & \multicolumn{2}{|c|}{ Control } & \multicolumn{2}{|c|}{ SPR } & \multirow{2}{*}{ Chi square } & \multirow{2}{*}{$p$} \\
\hline & & + & - & + & - & & \\
\hline TCC & 0.400 & 298.6 & 441.4 & 154.7 & 239.3 & 0.13 & 0.72 \\
\hline CAC & 0.275 & 213.4 & 526.6 & 98.3 & 295.7 & 1.95 & 0.16 \\
\hline CAT & 0.166 & 110.6 & 629.4 & 77.7 & 316.3 & 4.23 & 0.039 \\
\hline CCC & 0.157 & 117.0 & 623.0 & 61.0 & 333.0 & 0.02 & 0.88 \\
\hline
\end{tabular}

DRD2, dopamine receptor D2; SNP, singe nucleotide polymorphism; SPR, schizophrenia.

Haplotypes comprised of rs4648317, rs7131056, and rs4936270. Bold number indicates significant association. 
Table 4. Genotype and allele frequencies of DRD2 SNPs in European and Asian populations

\begin{tabular}{|c|c|c|c|c|c|c|c|}
\hline \multirow{2}{*}{ SNP } & & \multirow{2}{*}{ Type } & \multicolumn{2}{|c|}{ Korean* } & \multirow{2}{*}{ CEU (\%) } & \multirow{2}{*}{ HCB (\%) } & \multirow{2}{*}{ JPT (\%) } \\
\hline & & & $\mathrm{n}$ & $\%$ & & & \\
\hline \multirow{5}{*}{$\begin{array}{l}\text { rs } 4648317 \\
\text { Intron }\end{array}$} & Genotype & $\mathrm{C} / \mathrm{C}$ & 133 & 36.0 & 75.2 & 41.9 & 44.2 \\
\hline & & $C / T$ & 175 & 47.3 & 23.0 & 37.2 & 40.7 \\
\hline & & $\mathrm{T} / \mathrm{T}$ & 62 & 16.8 & 0.02 & 20.9 & 15.1 \\
\hline & Allele & C & 441 & 59.6 & 86.7 & 60.5 & 64.5 \\
\hline & & $T$ & 299 & 40.4 & 13.3 & 39.5 & 35.5 \\
\hline \multirow{5}{*}{$\begin{array}{l}\text { rs } 1076562 \\
\text { Intron }\end{array}$} & Genotype & $A / A$ & 95 & 25.7 & 5.3 & 16.3 & 26.7 \\
\hline & & $A / G$ & 181 & 48.9 & 36.3 & 58.1 & 50.0 \\
\hline & & $G / G$ & 94 & 25.4 & 58.4 & 25.6 & 23.3 \\
\hline & Allele & A & 371 & 51.2 & 23.5 & 45.3 & 51.7 \\
\hline & & $G$ & 369 & 49.9 & 76.5 & 54.7 & 48.3 \\
\hline \multirow{5}{*}{$\begin{array}{l}\text { rs } 4936270 \\
\text { Intron }\end{array}$} & Genotype & $\mathrm{C} / \mathrm{C}$ & 271 & 73.2 & 76.1 & 55.8 & 53.5 \\
\hline & & $\mathrm{C} / \mathrm{T}$ & 87 & 23.5 & 23.9 & 41.9 & 38.4 \\
\hline & & $\mathrm{T} / \mathrm{T}$ & 12 & 3.2 & - & 2.3 & 8.1 \\
\hline & Allele & C & 629 & 85.0 & 88.1 & 76.7 & 72.7 \\
\hline & & $T$ & 111 & 15.0 & 11.9 & 23.3 & 27.3 \\
\hline rs7131056 & Genotype & $\mathrm{C} / \mathrm{C}$ & 121 & 32.7 & 18.6 & 18.6 & 27.9 \\
\hline \multirow[t]{4}{*}{ Intron } & & $C / A$ & 174 & 47.0 & 48.7 & 53.5 & 48.8 \\
\hline & & $A / A$ & 75 & 20.3 & 32.7 & 27.9 & 23.3 \\
\hline & Allele & C & 416 & 56.2 & 42.9 & 45.3 & 52.3 \\
\hline & & A & 324 & 43.8 & 57.1 & 54.7 & 47.7 \\
\hline
\end{tabular}

DRD2, dopamine receptor D2; SNP, singe nucleotide polymorphism; CEU, Utah residents with Northern and Western European ancestry from the CEPH collection; CCB, Han Chinese in Beijing, China; JPT, Japanese in Tokyo, Japan.

${ }^{*}$ Control subjects in this study (http://www.ncbi.nlm.nih.gov/projects/SNP).

schizophrenia $\left(\chi^{2}=8.91, p=0.011\right){ }^{21)}$ The rs2734839 iSNP was reported to have an association with schizophrenia with late onset age. ${ }^{22)}$ Lee et al $^{23)}$ showed that rs 1799978 (promoter SNP), rs4245149 (iSNP), and rs4620755 (iSNP) were not associated with schizophrenia in Korean population.

Focusing on the our tested SNPs, rs4648317 was associated with better performance on the stop task in the drug free condition and lower scores on the impulsivity subscale. ${ }^{24)}$ Laucht et al ${ }^{25)}$ found that carriers of the T allele of rs4648317 were higher rates of current smoking and scored higher on nicotine dependence than their allelic counterparts. Völter et al. ${ }^{26)}$ reported that rs4648317 was related to prepulse inhibition of the acoustic startle response in the Munich sample, but not in the London sample. A Finnish population-based cohort showed an association between rs7131056 and social phobia $(p=0.0084) .{ }^{27)} \mathrm{Todt}$ et $a{ }^{28)}{ }^{28}$ reported that rs7131056 was associated with migraine with aura in a large German migraine with aura case-control sample (uncorrected allelic $p=0.0018$, $\mathrm{OR}=1.28$ ). However, this correlation did not conform in 2,937 British control individuals. The rs7131056 iSNP was reported to have initial significant association with nicotine dependence in European Americans, but not after correction for multiple testing, indicating a weak associa- tion of rs7131056 with nicotine dependence. ${ }^{29)}$ Xing et $a l^{30)}$ reported that rs1076562 did not show any association with the response to risperidone in Chinese patients with schizophrenia.

A famous SNP as known as TaqI DRD2 (rs1800497) is located within exon 8 of the adjacent gene, ankyrin repeat and kinase domain containing 1 (ANKK1). Therefore, we did not discuss about rs1800497 studies in this study.

In conclusion, we investigated whether four iSNPs (rs4648317, rs7131056, rs4936270, and rs1076562) of DRD2 are associated with schizophrenia in Korean population. We found that the genotype distribution of rs4936270 was associated with schizophrenia $\left(p^{c}=0.0028\right.$ in the codominant 1 model; $p^{c}=0.044$ in the dominant model) and the CAT haplotype was different between schizophrenia and controls ( $p=0.039$ ). These results suggest that rs4936270 of DRD2 may be associated with the susceptibility of schizophrenia. To confirm our results, replication studies of a large number of cases and/or additional studies of other DRD2 SNPs will be required.

\section{Acknowledgments}

This work was supported by a grant from Kyung Hee University in 2009 (KHU-20090641). 


\section{REFERENCES}

1. Casey DA, Rodriguez M, Northcott C, Vickar G, Shihabuddin L. Schizophrenia: medical illness, mortality, and aging. Int J Psychiatry Med 2011;41:245-251.

2. Petronis A. The origin of schizophrenia: genetic thesis, epigenetic antithesis, and resolving synthesis. Biol Psychiatry 2004;55:965-970.

3. Shih RA, Belmonte PL, Zandi PP. A review of the evidence from family, twin and adoption studies for a genetic contribution to adult psychiatric disorders. Int Rev Psychiatry 2004;16:260-283.

4. Gejman PV, Sanders AR, Kendler KS. Genetics of schizophrenia: new findings and challenges. Annu Rev Genomics Hum Genet 2011;12:121-144.

5. Gejman PV, Sanders AR, Duan J. The role of genetics in the etiology of schizophrenia. Psychiatr Clin North Am 2010;33:35-66.

6. Yamada K, Iwayama Y, Toyota T, Ohnishi T, Ohba H, Maekawa M, et al. Association study of the KCNJ3 gene as a susceptibility candidate for schizophrenia in the Chinese population. Hum Genet 2012;131:443-451.

7. Malhotra D, McCarthy S, Michaelson JJ, Vacic V, Burdick $\mathrm{KE}$, Yoon S, et al. High frequencies of de novo $C N V$ s in bipolar disorder and schizophrenia. Neuron 2011;72:951963.

8. Yue WH, Wang HF, Sun LD, Tang FL, Liu ZH, Zhang HX, et al. Genome-wide association study identifies a susceptibility locus for schizophrenia in Han Chinese at 11p11.2. Nat Genet 2011;43:1228-1231.

9. Neville MJ, Johnstone EC, Walton RT. Identification and characterization of ANKK1: a novel kinase gene closely linked to DRD2 on chromosome band 11q23.1. Hum Mutat 2004;23:540-545.

10. Usiello A, Baik JH, Rougé-Pont F, Picetti R, Dierich A, LeMeur M, et al. Distinct functions of the two isoforms of dopamine D2 receptors. Nature 2000;408:199-203.

11. Camps M, Cortés R, Gueye B, Probst A, Palacios JM. Dopamine receptors in human brain: autoradiographic distribution of D2 sites. Neuroscience 1989;28:275-290.

12. Toda M, Abi-Dargham A. Dopamine hypothesis of schizophrenia: making sense of it all. Curr Psychiatry Rep 2007;9: 329-336.

13. Murray RM, Lappin J, Di Forti M. Schizophrenia: from developmental deviance to dopamine dysregulation. Eur Neuropsychopharmacol 2008;18(Suppl 3):S129-S134.

14. Howes OD, Kapur S. The dopamine hypothesis of schizophrenia: version III-the final common pathway. Schizophr Bull 2009;35:549-562.

15. Heinz A, Schlagenhauf F. Dopaminergic dysfunction in schizophrenia: salience attribution revisited. Schizophr Bull 2010;36:472-485.

16. Zhang AP, Yu J, Liu JX, Zhang HY, Du YY, Zhu JD, et al. The DNA methylation profile within the 5'-regulatory region of DRD2 in discordant sib pairs with schizophrenia. Schizophr Res 2007;90:97-103.

17. Betcheva ET, Mushiroda T, Takahashi A, Kubo M, Karachanak SK, Zaharieva IT, et al. Case-control association study of 59 candidate genes reveals the DRD2 SNP rs6277 (C957T) as the only susceptibility factor for schizophrenia in the Bulgarian population. J Hum Genet 2009;54:98-107.

18. Fan H, Zhang F, Xu Y, Huang X, Sun G, Song Y, et al. An association study of DRD2 gene polymorphisms with schizophrenia in a Chinese Han population. Neurosci Lett 2010;477:53-56

19. Arinami $\mathrm{T}$, Itokawa $\mathrm{M}$, Enguchi $\mathrm{H}$, Tagaya $\mathrm{H}$, Yano $\mathrm{S}$, Shimizu H, et al. Association of dopamine D2 receptor molecular variant with schizophrenia. Lancet 1994;343:703704.

20. Glatt SJ, Faraone SV, Lasky-Su JA, Kanazawa T, Hwu HG, Tsuang MT. Family-based association testing strongly implicates DRD2 as a risk gene for schizophrenia in Han Chinese from Taiwan. Mol Psychiatry 2009;14:885-893.

21. Gupta M, Chauhan C, Bhatnagar P, Gupta S, Grover S, Singh PK, et al. Genetic susceptibility to schizophrenia: role of dopaminergic pathway gene polymorphisms. Pharmacogenomics 2009;10:277-291.

22. Voisey J, Swagell CD, Hughes IP, Lawford BR, Young RM, Morris CP. A novel DRD2 single-nucleotide polymorphism associated with schizophrenia predicts age of onset: HapMap tag-single-nucleotide polymorphism analysis. Genet Test Mol Biomarkers 2012;16:77-81.

23. Lee KY, Joo EJ, Ji YI, Kim DH, Park JB, Chung IW, et al. Associations between DRDs and schizophrenia in a Korean population: multi-stage association analyses. Exp Mol Med 2011;43:44-52.

24. Hamidovic A, Dlugos A, Skol A, Palmer AA, de Wit H. Evaluation of genetic variability in the dopamine receptor D2 in relation to behavioral inhibition and impulsivity/ sensation seeking: an exploratory study with d-amphetamine in healthy participants. Exp Clin Psychopharmacol 2009;17: 374-383.

25. Laucht M, Becker K, Frank J, Schmidt MH, Esser G, Treutlein J, et al. Genetic variation in dopamine pathways differentially associated with smoking progression in adolescence. J Am Acad Child Adolesc Psychiatry 2008;47:673681.

26. Völter C, Riedel M, Wöstmann N, Aichert DS, Lobo S, Costa A, et al. Sensorimotor gating and D2 receptor signalling: evidence from a molecular genetic approach. Int J Neuropsychopharmacol 2012;16:1-14.

27. Sipilä T, Kananen L, Greco D, Donner J, Silander K, Terwilliger JD, et al. An association analysis of circadian genes in anxiety disorders. Biol Psychiatry 2010;67:11631170.

28. Todt U, Netzer C, Toliat M, Heinze A, Goebel I, Nürnberg $\mathrm{P}$, et al. New genetic evidence for involvement of the dopamine system in migraine with aura. Hum Genet 2009; 125:265-279.

29. Huang W, Payne TJ, Ma JZ, Beuten J, Dupont RT, Inohara $\mathrm{N}$, et al. Significant association of ANKK1 and detection of a functional polymorphism with nicotine dependence in an African-American sample. Neuropsychopharmacology 2009; 34:319-330.

30. Xing Q, Qian X, Li H, Wong S, Wu S, Feng G, et al. The relationship between the therapeutic response to risperidone and the dopamine D2 receptor polymorphism in Chinese schizophrenia patients. Int J Neuropsychopharmacol 2007; 10:631-637. 